\title{
Caspian Oil and Regional Security
}

\author{
Malik Shonbayev ${ }^{1}$
}

Since gaining their independence in the early 1990s, the Caspian countries have intensified their activities in the exploitation of the natural resources of the Caspian Sea. This fact has drawn the attention of a number of countries (the U.S., Turkey, China, Middle Eastern countries) to the region. The main reason for this attention was the discovery of promising finds in a number of deposits as well as the launching of the pipeline of the Caspian Pipeline Consortium (CPC).

The confirmed resources of oil and gaseous condensate in the Caspian have been assessed at as much as 88 billion tons, and the natural gas deposits at 51 billion cubic meters. However, these assessments reflect only present knowledge about the depths of the Caspian Basin. So far only a few exploratory and prospective wells have been drilled on the perspective shelf structures. ${ }^{2}$

However, according to American Energy Agency forecasts, oil consumption in the world will increase by fifty percent by 2015 . Apart from this, the oil reserves of the Northern Sea will be sufficient for only the next 10-14 years, if the present rates of extraction remain constant. At that point, Western dependence on the Middle East's oil resources will increase. As for forecast assessments, there will be a ten-percent backlog in European demand for oil and natural gas by 2010, and a thirty-percent backlog by 2020 that will force Europe to look for new sources of hydrocarbon raw materials. In addition, substantial increases in the demand for energy resources in East, Southeast, and South Asia are expected. ${ }^{3}$

Under such conditions, the unsettled status of the Caspian Sea and the aggravated geopolitical struggle that has resulted, including disputes over transportation routes, problems associated with environmental preservation and biological resources, and the development of navigation and other economic activity could cause tension that could lead to conflict in the Caspian Sea region.

In the long term, the development of oil resources in the Caspian Sea, alongside similar development in other regions such as Latin America, will reduce the growth of the Middle Eastern share of global oil exports. Despite the fact that these Caspian resources will not drastically affect the position of the Persian Gulf zone as a leader in oil export, they will greatly affect the global market. For instance, the hydrocarbon resources of the continental part of Kazakhstan include 2.8 billion tons of oil and 1.8 trillion cubic meters of gas, including resources from such

\footnotetext{
${ }^{1}$ Malik Shonbayev is Chief Expert of the Security Council of the Republic of Kazakhstan.

2 "Vygoda - nash rulevoy" (Profit is Our Guide), February 23, 2001, at www.Rambler.ru.

3 "Vygoda - nash rulevoy" (Profit is Our Guide), February 23, 2001, at www.Rambler.ru.
} 


\section{THE QUARTERLY JOURNAL}

large deposits as Tengiz, with more than 1 billion tons of oil, and Karachaganak, with 1.3 trillion cubic meters of gas and nearly 700 million tons of condensate. ${ }^{4}$

There is no doubt that the countries of the Caspian region have high hopes for the development of the hydrocarbon structures on the Caspian shelf. It is known that a consortium of international oil companies has received encouraging results from exploratory drilling in Eastern Kashagan. For instance, estimates for the future project around 13 billion tons of oil and 2 trillion cubic meters of gas for the Kazakhstan sector of the Caspian Sea alone. ${ }^{5}$ All of this testifies to good prospects for Kazakhstan as a leading petroleum manufacturer and exporter in the Caspian region.

Obviously, all Caspian Sea resources can be used only in the event that all Caspian countries respect each other's interests. Unfortunately, today it is not possible to consider the newly emerging security situation in this vast region as absolutely safe and stable, given the tensions in Afghanistan and Caucasus, to name only two situations. Moreover, relations between Azerbaijan and Iran have become seriously aggravated since last summer. In its turn, Turkey, a strategic U.S. ally in NATO, has promised to render military assistance to Azerbaijan should it be attacked by Iran. That is why the Caspian region has been a zone of potential instability for the last few years.

At present the situation is deteriorating. The events of September 11, 2001, followed by the anti-terrorist operation in Afghanistan, have become the catalyst for the emergence of radical geopolitical processes and the reshuffling of the spheres of influence in the world. This is especially evident in Central Asia. Today, for many reasons, this region is turning more and more into one of the most intense intersections for the collision of interests of the major powers.

Such a conclusion is determined by the influence of various factors, including:

- Presence of substantial reserves of hydrocarbon raw material;

- Unsettled legal status of the Caspian Sea

- Disagreements between some states over the ownership of some deposits;

- Disputes over transportation priority for routes of Caspian oil.

By all accounts, the increasing struggle for control over the Caspian oil resources is a deep-seated cause for what is happening today in Central Asia.

The strategic competition between the U.S., Russia, and China for influence in the region has brought more dividends to the United States at this point. Washington has succeeded in establishing a pro-American political regime in Afghanistan

\footnotetext{
4 "Novaya bitva za Kaspiy" (New Battle for the Caspian Sea), April 24, 2002, at www.Rambler.ru.

5 "Novaya bitva za Kaspiy" (New Battle for the Caspian Sea), April 24, 2002, at www.Rambler.ru.
} 
and long-term military bases in Central Asia and has become more active in studying the feasibility of a pipeline from the Caspian regions, in particular, using the Afghanistan-Pakistan-Indian Ocean route.

Russia, although a late arrival on the scene, has enhanced its activity in the region within the framework of the Euro-Asian Economic Union and in the field of security. The first important steps have begun to be made in the area of security cooperation. The session of the Council for Collective Security, held in May in Moscow, approved the decision to transform the Treaty on Collective Security (NCS) into an international regional organization. China is also making efforts to restore the almost forgotten project for building a Western Kazakhstan-Western China Pipeline, which could be stretched in the future to India through Kashmir, by-passing Afghanistan.

The problem in developing Caspian oil and gas deposits is connected with the territorial issues of all five Caspian states: Azerbaijan, Iran, Kazakhstan, Russia, and Turkmenistan. From the disintegration of the Soviet Union until now, the issues relating to the legal status of the Caspian Sea have still remained unsettled. This has impeded the decision-making process concerning the division of the basin and its differentiation into national sectors. Accordingly, the development of the Caspian Sea deposits has been cast into doubt from a legal point of view.

The positions of Russia, Kazakhstan, and Azerbaijan on the issue of the division of the Caspian Sea on the median line are practically the same. Turkmenistan's position is quite close to theirs. But Iran's position remains constant: the Caspian Sea is to be divided into equal shares of twenty percent apiece. Additionally, until recently Iran has strongly objected to bilateral agreements. The Iranian side refers to the document accepted at a forum of five Caspian countries, held in 1996 in Ashkhabad, in which it was emphasized that any decision regarding legal status is to be made on the basis of consensus. ${ }^{6}$

As would be expected under such conditions, the Summit of Caspian States, held in April 2002 in Ashkhabad, did not produce any results. Because the pursuit of consensus seemed to be suspended in deadlock for a number of reasons, it became necessary for the parties to come to an agreement on a bilateral basis. Since then, the "pairs" of Russia-Kazakhstan, Azerbaijan-Russia, and Kazakhstan-Azerbaijan have succeeded in reaching an agreement; such success could be duplicated by Turkmenistan, Azerbaijan, and Iran.

Kazakhstan and Russia were the first to achieve a mutual understanding, most notably on the development of the Caspian seabed. The leaders of these states signed the Protocol of Agreement of July 6, 1998 on the differentiation of the northern part of the Caspian Sea with respect to rights of usage of mineral re-

\footnotetext{
6 "Pyat stran - pyat pozitsyi" (Five Countries-Five Positions), April 18, 2002, at www.Rambler.ru. 18. 04. 2002
} 
sources of the sea. ${ }^{7}$ Three hydrocarbon deposits that have been disputed before, and which are located on the modified median line, will be developed on the basis of parity. A similar protocol is scheduled for signing by Russia and Azerbaijan.

Iran, taking an uncompromising position and putting forward terms and conditions that are unacceptable to the other Caspian countries, has considerably slowed down the process of definition of the legal status of the Caspian Sea, to the disappointment of Western companies in the region who would like to get involved. And this in many respects complicates the resolution of the issue of investments for the development of oil and gas deposits and transportation matters. If President Niyazov agrees to negotiate and conclude agreements in a bilateral format (and this is of paramount importance for Ashkhabad in order to attract investments), Tehran will have to come to terms with the coordinated action of the countries of the Commonwealth of Independent States, which are well aware of the necessity of working out the new status of the Caspian Sea on the basis of a five-sided consensus. The subsequent process of definition of the legal status of the Caspian Sea would most likely follow.

The construction of a pipeline is the only possibility for the efficient transportation of these energy resources to foreign markets. The situation is complicated by the fact that the region has no natural access to the open sea, and thus to commodity markets, as well as by the fact that the internal political situation in many countries of the region has not yet stabilized. The construction of pipelines through the territory of neighboring states, in its turn, stipulates the necessity for long-term cooperation and the maintenance of regional stability.

In this situation the problem of choosing the routes for oil transportation could intensify. Then pressure would increase from the third parties interested both in the prompt realization of Caspian petroleum projects and in eliminating competitors in the hydrocarbon world market.

Today, for instance, the pipeline of the Caspian Pipeline Consortium (CPC) has been put into place. It transfers Kazakh oil from Tengiz to Novorossiysk. And it will suffice to have just one CPC pipeline in the near future for the export of all oil extracted today in Kazakhstan, provided its maximum project capacity reaches 67 million tons per annum. ${ }^{8}$

For its part, Kazakhstan, like the other Caspian states, is interested in the development of alternative routes for exporting its oil, for reasons including a desire to avoid Russian tariffs (recently Russia has increased the price for transportation of energy resources through its territory by thirteen percent). Turkmenistan and Azerbaijan are faced with the same problems.

The Chinese National Oil Company estimates that the demand for imported oil

\footnotetext{
${ }^{7}$ Kazakhstanskaya Pravda, May 28, 2002.

8 “Kontinent", No. 9, May 2002, 32.
} 
will reach $60-80$ million tons by $2010 .{ }^{9}$ As a result, the construction of the Western Kazakhstan-Western China pipeline is becoming an increasingly promising project.

Nobody doubted during the Euro-Asian Summit held recently in Almaty that the Iranian transit route for Caspian energy resources would be the most economically efficient. The Americans have said so as well. But, they asked, how can one assess the political risks while Iran supports global terrorism? Mr. Tokaev, head of Kazakhstan's Ministry of Foreign Affairs, appeased the participants by saying that the feasibility report for the export of Kazakh oil through Iran is now in progress. ${ }^{10}$

Some Caspian states, including Kazakhstan, could participate in the construction of the project, and then later in the maintenance of the Baku-Ceyhan pipeline. But not so much will depend on the political stability in the countries through which the pipeline passes, or on the U.S. military and political presence in Central Asia and the South Caucasus. More important will be the rate of oil extraction in the Caspian sectors of Azerbaijan and Kazakhstan, since the profitability of this pipeline will depend on it being constantly full. There has not been any significant success so far in realizing this vision. The Central Asian states, while choosing their own route for the transportation of their oil, will be guided, most likely, by economic rather than political motives. Such a position is dictated by the present economic situation in the region.

The priority route for oil transportation to foreign markets will depend on this choice. Only the future will show which will prevail: the CPC, Baku-Ceyhan, or any other route.

Now that projects in the Caspian Sea have been set into motion, the issues of preserving the environmental balance in the region are becoming increasingly important. Among the most relevant issues in the Caspian territory are the following: the decrease of resource potential of water and ground ecosystems, threat of disappearance of ecosystems for food animals including different kinds of sturgeon, and decrease of specific species of flora and fauna.

From among the numerous environmental issues that have been identified, the following are the most significant:

- Pollution of the Caspian Sea (in connection with a rise in sea level) causing flooding and partial flooding of the units of the oil-and-gas and energy complex;

- Exhaustion of underground water resources as a result of uncontrolled water extraction for drinking and technical needs;

\footnotetext{
9 "Kontinent", No. 9, May 2002, 33

10 "Kazakhstanskaya Pravda", April 09, 2002
} 
- Pollution and degradation of soil-and-vegetation cover as a result of economic activity;

- Air pollution caused by the burning of casing-head gas and as a result of emissions of toxic industrial wastes;

- Absence of legal regulation of environmental issues of the Caspian Sea at a regional level;

- Absence of an integrated database for optimum control over water and coastal ecosystems;

- Weak regional cooperation for preserving the Caspian ecosystems.

Thus, the position of the Central Asian countries has remained and still remains constant: the Caspian Sea area must become a zone of cooperation.

In view of the intensifying competition in the sales markets for energy carriers, the availability of alternate routes for hydrocarbon transportation represents one of the main ways of decreasing the degree to which the region is buffeted by world geopolitical conditions and to strengthen the independence of the countries of Central Asia.

Kazakhstan still adheres to its initial position based on respect of the principles of international law and the use of international expertise. We realize that the precise clarification of national jurisdictions in the Caspian Sea will promote the strengthening of regional security and the development of cooperation. Under the conditions of irreconcilable rivalry, lack of compromise, and stalling the process of defining the status of the Caspian Sea-elements of which now prevail-the countries and people of the region feel uneasy, to put it mildly. The future of the Caspian Sea should be based on the common values and agreed-upon principles of mutual relations between the states, which are aimed at adopting a system of regional security and cooperation.

Each country will best achieve the implementation of its own interests through the means of regional cooperation. This is the most effective way, as has been demonstrated by world experience. If the countries of the Caspian basin create a regional organization and lay oil pipelines around the Caspian Sea, they will manage their own oil production and choose the best route for its export. The bulk of the oil of the Caspian Sea will then go to the international market, and thus it the region will realize a huge economic gain. That is why the most successful choice is universal cooperation. To sum up, I would like to note that today the primary goal for all the Central Asian countries in the Caspian basin is to use the hydrocarbon resources sensibly with the view of achieving stability and prosperity in our countries, thereby increasing the well-being of our peoples. 


\section{Bibliography}

Vygoda nash rulevoy In Pro $t$ is Our Guide. Rambler.ru, 2001.

Novaya bitva za Kaspiy In New Battle for the Caspian Sea. Rambler.ru, 2002.

Pyat stran pyat pozitsyi In Five Countries Five Positions. Rambler.ru, 2002. 